\title{
Does perineal body thickness affect faecal incontinence in multiparous patients?
}

\author{
A M A H Alhurry, ${ }^{1} \mathrm{MD}$; M A Akool, ${ }^{2} \mathrm{MD} ; \mathrm{S}$ V Hosseini, ${ }^{3} \mathrm{MD} ;$ H Khazraei, ${ }^{3} \mathrm{PhD} ; \mathrm{L}$ Moosavi,${ }^{3} \mathrm{MS} ;$ S Pourahmad, ${ }^{4} \mathrm{PhD}$
}

${ }^{1}$ Department of General Surgery, Al Hussein Teaching Hospital, Kerbala, Iraq

${ }^{2}$ Department of Surgery, Medical College, Jabir Ibn Hayyan Medical University, Najaf, Iraq

${ }^{3}$ Colorectal Research Center, Shiraz University of Medical Sciences, Shiraz, Iran

${ }^{4}$ Department of Biostatistics, Shiraz University of Medical Sciences, Shiraz, Iran

Corresponding author: H Khazraei (hajarkhazraei@gmail.com)

Background. Obstetric trauma is the most common cause of faecal incontinence in multiparous women. The literature has shown that women with obstetric trauma to the anal sphincter have decreased perineal body thickness (PBT).

Objective. To determine the role of PBT in the assessment of this type of faecal incontinence in multiparous patients.

Methods. Forty-four women with faecal incontinence, and 36 asymptomatic women who had had two or more previous deliveries, were investigated with endoanal ultrasonography from January to December 2016. The patients were divided into three groups on the basis of PBT: $<10 \mathrm{~mm}, 10-12 \mathrm{~mm}$ and $>12 \mathrm{~mm}$. The degree of faecal incontinence was measured using the Wexner faecal incontinence score. Sphincter angle defect was separately measured for each patient.

Results. The mean (standard error) age of all of our 80 patients was 46.9 (1.3) years (range 26 - 77 years), and the mean PBT in incontinent patients was $8.78(2.84) \mathrm{mm}$, and $12.65(16.76) \mathrm{mm}$ in asymptomatic subjects $(p<0.001)$. The mean Wexner score was 8.6 (range 2 - 20) in incontinent patients. External anal sphincter defect angles were negatively correlated with PBT ( $p=0.045$ ). For $89 \%$ of the patients, there was a history of vaginal delivery, and $62.5 \%$ had undergone one or more prior episiotomies during delivery. A PBT $<10 \mathrm{~mm}$ was associated with sphincter defect in most incontinent patients.

Conclusion. PBT plays a significantly important role in faecal incontinence, so it is recommended that it should be one of the factors involved in anal incontinency evaluations.

S Afr J Obstet Gynaecol 2018;24(3):79-82. DOI:10.7196/SAJOG.2018.v24i2.1305

Faecal incontinence is the involuntary loss of faeces at an unexpected moment or place. Flatus may also be included in the definition. It is a social and hygienic problem affected by anatomical and physiological factors. Faecal incontinence has an incidence of about $1-10 \%$ in the adult population. ${ }^{[1]}$ It occurs principally in the elderly and female population, and can have a devastating effect on a woman's quality of life. Unfortunately, women do not report their symptoms; therefore, the actual incidence of the problem is unknown. ${ }^{[2]}$ Obstetric trauma is the most common cause of faecal incontinence in women, but its aetiology can be congenital, neurological or idiopathic. ${ }^{[3,4]}$

It remains to be established whether obstetric trauma after two or more vaginal deliveries is a risk factor for developing incontinence later in life. Although the risk of new injury and defecatory symptoms occurring in subsequent normal deliveries is small (4\%), $42 \%$ of asymptomatic women who have a pre-existing occult defect may develop impaired continence following a subsequent vaginal delivery, within 2 months of this delivery. ${ }^{[1]}$ This impaired continence could be the result of a change in diet and bowel habits, ageing, anorectal surgery, haemorrhoids or irritable bowel syndrome.

Anatomically, in women, the perineal body separates the anal canal from the urogenital diaphragm in the median plane where the deep bulbospongiosus and superficial transverse perineal muscles meet the external anal sphincter (EAS). ${ }^{[3,4]}$ The presence of a considerably bulky, tensile perineal body can be confirmed by the presence of a normal anal sphincter complex. A perineal body thickness (PBT) $\leq 10 \mathrm{~mm}$ is considered abnormal, according to the endosonographic perineal body measurement described by Zetterström et al. ${ }^{[5]}$

Anal endosonography is the gold standard in imaging the sphincter, and has superseded conventional electromyography mapping in the diagnosis of anal sphincter defects. ${ }^{[1]}$ Endoanal ultrasound (EAUS) has revolutionised our understanding of the pathophysiology of faecal incontinence. Since its invention by Low and Bartram in 1989, ${ }^{[6]}$ EAUS has been found to be superior to other diagnostic tools, with $100 \%$ sensitivity in detecting sphincter defects. ${ }^{\left[{ }^{[]}\right.}$At the proximal anal canal, in $98 \%$ of women the EAS is shorter interiorly compared with the posterior area. ${ }^{[8,9]}$ Where the EAS fibres slope anteriorly, an apparent anterior anal sphincter defect (ASD) may be detected, with a liability of obstetric injury in the internal anal sphincter (IAS). ${ }^{[1]}$

In the distal anal canal, the IAS is thin; therefore, we measured the PBT, anterior anal sphincter defect and anal sphincter defect angle (ASDA) at the level of the mid-anal canal, which can be clearly delineated by the presence of the most prominent hypoechoic ring of the IAS. ${ }^{[1]}$

The aim of this study was to determine the role of PBT in the assessment of a group of multiparous patients who had undergone 
deliveries more than once, and had developed obstetric faecal incontinence, as well as in those who had not developed this problem.

\section{Patients and methods}

One hundred and twenty multiparous patients, with and without faecal incontincence, underwent EAUS for evaluation of PBT, ASD, ASDA and anal manometry between January and December 2016, in a prospective clinical study at the colorectal subspecialty department in Shahid Faghihi Hospital, Shiraz, Iran.

The exclusion criteria were patients who were nulliparous and primiparous; those with previous radiation, low colorectal anastomosis, diabetes mellitus, ulcerative colitis, Crohn's disease and neurological disease; those with chronic constipation or diarrhoea, hypo- or hyper-thyroidism, hypo- or hyper-parathyroidism; and those who had undergone perineal or prolapse surgery such as sphincteroplasty, sphincterotomy, perineoplasty or pelvic floor repair.

Age, obstetric history and degree of incontinence were recorded for each patient. The degree of faecal incontinence was measured using Wexner's incontinence scale $(0-20)$. The patients were placed in the left lateral decubitus position. As a standard protocol, we started our examination with anal manometry, followed by EAUS. In this study, perineal body thickness, anal sphincter maximum squeezing pressure, mean resting pressure (MRP), external anal sphincter defect (EASD) and external anal sphincter defect angle (EASDA) were evaluated.

For more detailed evaluation, the patients were subdivided into three groups according to $\mathrm{PBT}<10 \mathrm{~mm}, 10-12 \mathrm{~mm}$ and $>12 \mathrm{~mm}$.

\section{Anal manometry}

This was performed by a special-purpose sphinctometer system (Promedico, Germany, Version 1.51). This device allows quick and precise measurements of anal sphincter muscle tone during relaxation and squeezing condition. The measured value can be read off the device after inserting a specific sensor in the anal canal. The sphinctometer's effective range is between 0 and $300 \mathrm{mmHg}$.

\section{Endoanal ultrasound}

A two-dimensional EAUS machine using a Bruel and Kjaer medical ultrasound scanner (Herlev, Denmark) Merline Type 1101, with a 2050 model of 360-degree rotating endoprobe transducer, was used. The transducer frequency range was $3.75-20 \mathrm{MHz}$. EAUS was performed by an endoprobe covered with the middle finger of a disposable latex surgical glove, with ultrasound gel applied to both surfaces and introduced into the rectum. The ultrasound picture was controlled by two buttons in the proximal part of the endoprobe handle in the upward and downward direction through the anal canal, in a panoramic view.
Sonographically, the anal canal is divided into three levels: the upper level, determined by the U-shaped puborectalis muscle sling that opens anteriorly; the middle level, where the IAS is at its greatest thickness; and the lower level, which is determined by maximum thickness of the subcutaneous EAS and thinnest IAS.

\section{Digit-assisted EAUS}

A gloved lubricated finger was inserted into the vagina, touching the posterior wall with gentle pressure, while the endoprobe was in the anal canal; during the process, the EASD, external anal sphincter defect angle (EASDA) and PBT were evaluated at the mid-anal canal level ${ }^{[5,10,11]}$ on a frozen ultrasound picture. No bowel preparation was done before the procedure.

The EASD is a homogenous hypoechoic or mixed echogenicity defect within the external muscle ring, scarring presenting as a change in echogenicity, which was not described as a defect. ${ }^{[5]}$ The EASDA is described as the maximum angle of separation of the edge of the defect, and measured from the centre of the probe. ${ }^{[5,10]}$ The PBT is defined as the distance between the sonographic reflection of the gloved index finger and the inner border of the IAS at the midanal canal level. ${ }^{[3,5]}$

Endoanal manometry was performed by the colorectal nurse specialist, and EAUS was performed by a single operator who was a colorectal surgeon, and the results were evaluated by two experienced endoanal sonographic colorectal surgeons. The study was approved by the ethics committee of Shiraz University of Medical Sciences (ref. no. 10834).

\section{Statistical analysis}

All statistical analyses were performed using Statistical Package for Social Sciences software version 15 (SPSS, USA). Quantitative data were analysed by $t$-test or analysis of variance. The correlation between groups for the categorised variables was analysed by $\chi^{2}$ tests or the Pearson or Spearman correlation test. A $p$ value $<0.05$ was considered statistically significant.

\section{Results}

Only 80 patients fulfilled the inclusion criteria (multiparous patients who voluntarily accepted the study procedure and completed the consent form), and these were categorised into two groups. Group 1 comprised 44 patients who had already presented with faecal incontinence due to obstetrical injuries. Group 2 consisted of 36 subjects who were asymptomatic (Table1).

Post hoc calculation by power analysis on the effect size of 1.13 (for PBT difference) showed $85 \%$ power for at least 36 cases in each group. In our study, 80 multiparous women with a mean age of 46.9 years (range 26 - 77 years) who had had two or more previous deliveries underwent EAUS and PBT measurement.

Table 1. Data from patients in clinical continent and incontinent groups shown by mean (SE)

\begin{tabular}{|c|c|c|c|}
\hline Patient characteristic & Incontinent $(n=44)$ & Continent $(n=36)$ & $p$-value \\
\hline Age (years) & $47.9(1.8)$ & $45.7(1.8)$ & 0.395 \\
\hline Squeezing pressure $(\mathrm{mmHg})$ & $65.1(5.1)$ & $91.7(5.7)$ & 0.001 \\
\hline Mean resting pressure $(\mathrm{mmHg})$ & $18.4(2.0)$ & $30.6(1.9)$ & $<0.001$ \\
\hline PBT (mm) & $8.78(0.4)$ & $9.91(0.2)$ & 0.035 \\
\hline Digital angle degree of anal sphincter defect $\left(^{\circ}\right)$ & $104.9(5.78)$ & $91.64(5.41)$ & 0.14 \\
\hline
\end{tabular}




\section{PBT and symptoms of faecal incontinence}

The mean Wexner score among incontinent patients was 8.6 (0.7) (range 2 - 20). The mean duration of incontinence was 50.3 (12.1) months. EAUS showed a PBT $\leq 10 \mathrm{~mm}$ for 48 (60\%) out of 80 patients. Twenty-four (30\%) patients had a PBT $10-12 \mathrm{~mm}$, and $8(10 \%)$ had a PBT $>12 \mathrm{~mm}$. The means of resting pressure and squeezing pressure were significantly different between continent and incontinent patients. PBT showed positive significant correlations with MRP $(r=0.336 ; p=0.001)$, squeezing pressure $(r=0.45 ; p=0.045)$ and age $(r=0.297 ; p=0.009)$ and a negative relationship with Wexner score $(r=-0.219 ; p=0.051)$, duration of disorder $(r=-0.293 ; p=0.008)$ and EASDA $(r=-0.301 ; p=0.045)$ (Table 2 ). From these figures, the significant results derived for the positive relationship between PBT and age, and negative relationship between PBT and duration of disorder, are clinically interesting.

Twenty-two patients in the group with PBT $<10 \mathrm{~mm}$ were incontinent, with a sphincter defect, and 8 of the 22 had a Wexner score of 10 - 20. Six incontinent patients with PBT $10-12 \mathrm{~mm}$ had a sphincter defect, and 3 of these had a Wexner score of $10-20$. Three incontinent patients with PBT $>12 \mathrm{~mm}$ had an EASD, and 2 of these had a Wexner score of 10 - 20. There were no significant differences among the three groups in Wexner score or EASDA in incontinent patients. However, squeezing pressure was significantly different among these three groups (analysis of variance $F=4.93, p=0.01$ ).

When patients were divided into two groups based on EASD, 45 patients showed a defect, while 35 did not, and PBT was significantly different between the groups (absolute mean difference (standard error $(\mathrm{SE}))=1.23(0.5) ; p=0.015)$. Furthermore, MRP was significantly different (absolute mean difference (SE) = 8.23 (3.0); $p=0.008$ ), but squeezing pressure was not significantly different $(p=0.138)$.

An EASDA in the range of $40-195^{\circ}$ (mean $100.8^{\circ}$ ) was found in $56.25 \%$ of the patients, and was distributed across the groups as follows: $29(60.42 \%)$ of 48 patients with a PBT $<10 \mathrm{~mm}, 12(50 \%)$ of 24 patients with a PBT $10-12 \mathrm{~mm}$, and $4(50 \%)$ of 8 patients with a PBT $>12 \mathrm{~mm}\left(\chi^{2}=0.847 ; p=0.65\right)$.

An increased EASDA was found in 41 (90.9\%) of 45 women with a defective anal sphincter who were incontinent. Fourteen patients with an increased EASDA were not clinically incontinent, and there was no significant difference between continent and incontinent patients $(p=0.14)$.

\section{Discussion}

Our study evaluated faecal incontinence, PBT and EASD in multiparous women. The study demonstrated that in a group of incontinent women, a sonographically 'thin' perineal body (PBT $<10 \mathrm{~mm}$ ) was associated with an ASD in $73.3 \%$ of the cases. This result is in agreement with previously published findings in parous patients. $^{[5]}$

Incontinence is a multifactorial condition, including changes in stool consistency and volume, decreased anorectal sensation and angle, lack of a compliant reservoir, disruption of anal sphincter integrity, pudendal nerve neuropathy and mental function. It is defined by two mechanisms - direct injury (more often during the first delivery, after which $35 \%$ of women develop occult sphincter injury, and may experience symptoms of urgency and transient incontinence), and traction neuropathy of the pudendal nerves ( $42 \%$ with subsequent vaginal deliveries and with a sphincter defect may develop impaired continence). ${ }^{[12-15]}$ It is now established that occult or unrecognised mechanical disruption to the anal sphincter is a major aetiological factor. ${ }^{[1]}$ In our study, the mean number of vaginal deliveries was 3 (range 2 - 15), while in a study by Zettersröm et al., ${ }^{[5]}$ it was 2.3 (range $1-6$ ). In a study by Titi et al. ${ }^{[1]]}$ it was 2 (range 1 - 3). In our results, some patients had undergone one or more prior episiotomies during delivery that may have greatly contributed to an anterior external sphincter defect and affected PBT (Table 3).

Zetterström et al. ${ }^{[5]}$ measured the PBT (12.2 (SE 3.5 ) mm) in asymptomatic primigravida subjects without EAUS evidence of sphincter injury in their first trimester, and defined this as normal $\mathrm{PBT}$, while $\mathrm{PBT} \leq 10 \mathrm{~mm}$ was considered abnormal, and was found in 93\% (39 of 42) of incontinent women with an obstetric trauma to the anal sphincter.

In our results, the PBT was significantly different between continent and incontinent patients, although some overlap between the groups did occur. There were significant relationships between $\mathrm{PBT}$ and MRP and squeezing pressure, which was not found in the study by Titi et al. ${ }^{[1]}$ The IAS is responsible for $50-85 \%$ of the resting tone ${ }^{[16]}$ even in the presence of an intact EAS; this relationship may explain the importance of the IAS in obstetric damage. ${ }^{[16]}$

An EASD was shown in $56 \%$ of patients during EAUS. We also found that there was a significant negative correlation between PBT and EASD, which means that a thin perineal body is associated with a large angle of sphincter defect. Thinning of the perineal body is a well-known clinical finding among incontinent women with a sphincter defect.

PBT was divided into three groups. PBT $<10 \mathrm{~mm}$ was found in $48(60 \%)$ multiparous patients, and 30 patients $(62.5 \%)$ were incontinent in this group. Although this percentage is lower than those found by other studies, ${ }^{[2,5,11]}$ in those studies all submitted patients were suffering from symptoms of incontinence, while in our current study 36 (45\%) of the patients were asymptomatic, demonstrating that there is an overlap with asymptomatic patients.

It should be noted that the other studies ${ }^{[2,5,11]}$ did not use the same exclusion criteria as those in our study, where perineal surgical repair, rectal surgery for prolapse and rectocele, and nulliparous

Table 2. Correlation between PBT measurements and other parameters

\begin{tabular}{lll}
\hline Parameter & PBT $(\boldsymbol{r})$ & $\boldsymbol{P}$-value \\
\hline MRP & $0.336^{*}$ & 0.001 \\
Squeezing pressure & $0.45^{*}$ & $<0.001$ \\
Wexner score & $-0.219^{\dagger}$ & 0.051 \\
Duration of disorder & $-0.293^{\dagger}$ & 0.008 \\
Age & $0.297^{*}$ & 0.009 \\
EASDA & $-0.301^{\dagger}$ & 0.045 \\
PBT = perineal body thickness; MRP = mean resting pressure; EASDA = external anal \\
sphincter defect angle. \\
*Pearson correlation coefficient. \\
'Spearman correlation coefficient.
\end{tabular}

Table 3. Possible aetiological factors for patients with anal sphincter defects, by PBT

\begin{tabular}{|c|c|c|c|c|}
\hline Factor $(n)$ & $\leq 10 \mathrm{~mm}$ & $10-12 \mathrm{~mm}$ & $>12 \mathrm{~mm}$ & $p$-value \\
\hline Incontinent & 30 & 8 & 6 & 0.031 \\
\hline Episiotomy & 30 & 12 & 8 & 0.165 \\
\hline Abortion & 4 & 4 & 1 & \\
\hline Sphincter defect & 29 & 12 & 4 & 0.655 \\
\hline
\end{tabular}


women were excluded, so the real significance of the PBT effect was not demonstrated.

Eighteen percent of incontinent patients had a PBT between 10 and $12 \mathrm{~mm}$, and $13.6 \%$ had a PBT $>12 \mathrm{~mm}$. Therefore, the largest group of incontinent patients with a sphincter defect was found to have a PBT $<10 \mathrm{~mm}$, while the smallest group had a PBT $>12 \mathrm{~mm}$; this is similar to the results of Zetterström et al'. $\mathrm{s}^{[5]}$ study. In our results, 22 patients in the group with reduced PBT were incontinent with a sphincter defect, and 8 of these had a Wexner score of 10 20; 6 incontinent patients with a PBT of between 10 and $12 \mathrm{~mm}$ had a sphincter defect, and 3 of these had a Wexner score of $10-20$. Therefore approximately two-thirds of women with incontinence had a reduced PBT.

A significant negative correlation was found between PBT and age. Primary degeneration of the IAS could be the cause of thinning in the sphincter muscles of elderly patients. ${ }^{[17]}$ Titi et al. ${ }^{[11]}$ evaluated 90 women with faecal incontinence, and found no evidence of increasing EASD, with a thinner perineal body, with age. In some studies, there was no significant relationship between the perineal body and the Wexner score, i.e. the degree of faecal incontinence. ${ }^{[2,11,18]}$ The reasons for this are not clear. Mechanisms that maintain continence are multifactorial, and certainly in our study there were patients with a thin PBT who remained continent.

Continence is an interesting and complicated process, and patients clinical data may show different results from laboratory-observed variables (endoanal manometry and EAUS). In the management of incontinence, anal physiology plays an important role, and biofeedback therapy in patients may improve physiological function and increase the power of the anal muscles to achieve continence. In our experience, patients with an adequate perineal body may represent a group who respond better to conservative measures, such as biofeedback therapy or sacral nerve stimulation, with its unknown mechanism, to cure incontinence, rather than immediate recourse to surgery. However, this has yet to be formally validated.

\section{Conclusion}

Faecal incontinence is a common but usually unrecognised medical problem in women, especially after traumatic vaginal deliveries. ${ }^{[14,15]}$ In our study, $56 \%$ of patients had a sphincter defect demonstrable by EAUS. There was no significant correlation between PBT and Wexner incontinence score. Finally, the routine addition of PBT measurement to EAUS in the evaluation of faecal incontinence may be worthwhile. We believe that PBT measurement is simple to perform, and should be included in the assessment of incontinence, which remains a multifactorial and complex problem.
Acknowledgements. We thank Fahimeh Hajhosseini and Shahla Fereydooni for their assistance with the colorectal procedures.

Author contributions. AMAHA: study design, data gathering, manuscript preparation, final approval. MAA: data gathering, data analysis, final approval. SVH: study design, manuscript preparation, revision, final approval. HK: study design, data analysis, manuscript preparation, revision, final approval. LM: data gathering, data analysis, final approval. SP: data analysis, manuscript preparation, revision, final approval.

Conflicts of interest. None.

Funding. None.

1. Thakar R, Sultan AH. Anal endosonography and its role in assessing the incontinent patient. Best Pract Res Clin Obstet Gynaecol 2004;18(1):157-173. https://doi.org/10.1016/j.bpobgyn.2003.09.007

2. Oberwalder M, Thaler K, Baig MK, et al. Anal ultrasound and endosonographic measurement of perineal body thickness: A new evaluation for faecal incontinence in females. Surg Endosc 2004;18(4):650-654. https://doi.org/10.1007/s00464-003-8138-5

3. Jorge JM, Wexner SD. Etiology and management of fecal incontinence. Dis Colon Rectum 1993;36(1):77-97.

4. Martínez Hernández Magro P, Villanueva Sáenz E, Jaime Zavala M, Sandoval Munro RD, Rocha Ramírez JL. Endoanal sonography in assessment of fecal incontinence following obstetric trauma. Ultrasound Obstet Gynecol 2003;22(6): 616-621. https://doi.org/10.1002/uog.919

5. Zetterström JP, Mellgren A, Madoff RD, Kim DG, Wong WD. Perineal body measurement improves evaluation of anterior sphincter lesions during endoanal ultrasonography. Dis Colon Rectum 1998;41(6):705-713

6. Law PJ, Bartram CI. Anal endosonography: Technique and normal anatomy. Gastrointest Radiol 1989;14(4):349-353.

7. Sultan AH, Nicholls RJ, Kamm MA, Hudson CN, Beynon J, Bartram CI. Anal endosonography and correlation with in vitro and in vivo anatomy. Br J Surg 1993;80(4):508-511.

8. Sultan AH, Kamm MA, Hudson CN, Nicholls JR, Bartram CI. Endosonography of the anal sphincters: Normal anatomy and comparison with manometry. Clin Radiol 1994;49(6):368-374.

9. Gold DM, Bartram CI, Halligan S, Humphries KN, Kamm MA, Kmoit WA. Three-dimensional endoanal sonography in assessing anal canal injury. Br J Surg 1999;86(3):365-370. https://doi. org/10.1046/j.1365-2168.1999.01041.x

10. Felt-Bersma RJ, Cuesta MA, Koorevaar M. Anal sphincter repair improves anorectal function and endosonographic image. A prospective clinical study. Dis Colon Rectum 1996;39(8):878-885.

11. Titi MA, Jenkins JT, Urie A, Molloy RG. Perineum compression during EAUS enhances visualisation of anterior anal sphincter defects. Colorectal Dis 2009;11(6):625-630. https://doi. org/10.1111/j.1463-1318.2008.01615.x

12. Fynes MM, Behan M, O’Herlihy C, O’Connell PR. Anal vector volume analysis complements endoanal ultrasonographic assessment of postpartum anal sphincter injury. $\mathrm{Br} \mathrm{J}$ Surg 2000;87(9):1209-1214. https://doi.org/10.1046/j.1365-2168.2000.01515.x

13. Fynes MM, Marshall K, Cassidy M, et al. A prospective, randomised study comparing the effect of augmented biofeedback with sensory biofeedback alone on fecal incontinence after obstetric trauma. Dis Colon Rectum 1999;42(6):753-758

14. Donnelly VS, Fynes M, Campbell D, Johnson H, O’Connell PR, O’Herlihy C. Obstetric events leading to anal sphincter damage. Obstet Gynecol 1998;92(6):955-961.

15. Fynes M, Donnelly V, Behan M, O'Connell PR, O'Herlihy C. Effect of second vaginal delivery on anorectal physiology and faecal continence: A prospective study. Lancet 1999;354(9183):983-986 https://doi.org/10.1016/S0140-6736(98)11205-9

16. Lestar B, Penninckx F, Kerremans R. The composition of anal basal pressure. An in vivo and in vitro study in man. Int J Colorectal Dis 1989;4(2):118-122.

17. Vaisey CJ, Kamm MA, Bartram CI. Primary degeneration of the internal anal sphincter as a cause of passive faecal incontinence. Lancet 1997;349(9052):612-615. https://doi.org/10.1016/S01406736(96)09188-X

18. Voyvodic F, Rieger NA, Skinner S, et al. Endosonographic imaging of anal sphincter injury: Does the size of the tear correlate with the degree of dysfunction? Dis Colon Rectum 2003;46(6):735-741. https://doi.org/10.1097/01.DCR.0000070042.82320.9F

Accepted 14 January 2019 